

\title{
Fast and wideband supercontinuum absorption spectroscopy in the mid-IR range
}

\author{
N. Cézard, G. Canat, A. Dobroc, M. Duhant, W. Renard, C. Besson
}

\section{To cite this version:}

N. Cézard, G. Canat, A. Dobroc, M. Duhant, W. Renard, et al.. Fast and wideband supercontinuum absorption spectroscopy in the mid-IR range. LACSEA, Jul 2014, SEATTLE, United States. hal01069622

\section{HAL Id: hal-01069622 \\ https://hal-onera.archives-ouvertes.fr/hal-01069622}

Submitted on 29 Sep 2014

HAL is a multi-disciplinary open access archive for the deposit and dissemination of scientific research documents, whether they are published or not. The documents may come from teaching and research institutions in France or abroad, or from public or private research centers.
L'archive ouverte pluridisciplinaire HAL, est destinée au dépôt et à la diffusion de documents scientifiques de niveau recherche, publiés ou non, émanant des établissements d'enseignement et de recherche français ou étrangers, des laboratoires publics ou privés. 


\title{
Fast and wideband supercontinuum absorption spectroscopy in the mid-IR range
}

\author{
N. Cézard, G. Canat, A. Dobroc, M. Duhant, W. Renard, C. Besson \\ ONERA, The French Aerospace Lab, F-91123 Palaiseau Cedex, France \\ Contact author: nicolas.cezard@onera.fr
}

\begin{abstract}
We report on our new test bench dedicated to Supercontinuum Absorption Spectroscopy in the mid-infrared $(3.3 \mu \mathrm{m})$. It delivers fast $(<0.1 \mathrm{~s})$ and wideband spectra $(200 \mathrm{~nm})$ at $0.8 \mathrm{~cm}^{-1}$ resolution. Gas concentrations are retrieved using a DOAS-inspired algorithm. OCIS codes: (300.0300) Spectroscopy; (300.1030) Absorption
\end{abstract}

\section{Introduction}

Supercontinuum absorption spectroscopy is an attractive technique for multi-species analysis of a gas mixture in open path (atmospheric remote sensing) [1] or for local sensing [2]. The main critical parts for this technique are i) the supercontinumm laser source, ii) the spectral analyzer and iii) the processing algorithm. We have addressed these three complementary topics to design and build a new test bench dedicated to supercontinuum spectroscopy in the mid-infrared range $(2-4 \mu \mathrm{m})$. It is called SHADOAS (Supercontinuum Light Generation for Differential Optical Absorption Spectroscopy). The mid-infrared range is a fingerprint region for important pollutants like $\mathrm{CH}_{4}$ and many other VOCs (Volatile Organic Compounds), especially in the 3-4 $\mu \mathrm{m}$ window.

\section{Mid-infrared supercontinuum laser source}

Our mid-IR supercontinuum (SC) laser source is composed of a fluoride fiber (ZBLAN) pumped by a short-pulse 2 $\mu \mathrm{m}$ laser. This wavelength stands beyond the zero dispersion wavelength of fluoride fibers $(\approx 1.6 \mu \mathrm{m})$, which is a necessary condition for soliton-induced SC shift toward the mid-IR to occur efficiently. The $2 \mu \mathrm{m}$ pump laser is a MOFPA (Master Oscillator Fiber Power Amplifier). The oscillator is made of a Thulium-Doped Fiber (TDF), and it delivers $2 \mathrm{~ns}$ pulses with $900 \mathrm{~W}$ peak power at $2 \mu \mathrm{m}$ with a $20 \mathrm{kHz}$ repetition rate. It is then amplified in a second TDF. The output peak power can reach up to $20 \mathrm{~kW}(0.8 \mathrm{~W} \mathrm{cW})$ at $2 \mu \mathrm{m}$. These pump pulses are then coupled into a fluoride step-index fiber ( $9 \mu \mathrm{m}$ core, $10 \mathrm{~m}$ length). Non-linear effects yield a supercontinuum of wavelengths at the fiber output, with a global power coupling of 50\%. The Power Spectral Density obtained is shown on Figure 1. The mid-IR continuum extends up to $4.25 \mu \mathrm{m}$ and is limited by the fiber transparency and $\mathrm{CO}_{2}$ absorption along the light path (slightly visible at $4.23 \mu \mathrm{m}$ ). About $70 \%$ of the coupled power is converted beyond $2.5 \mu \mathrm{m}$.

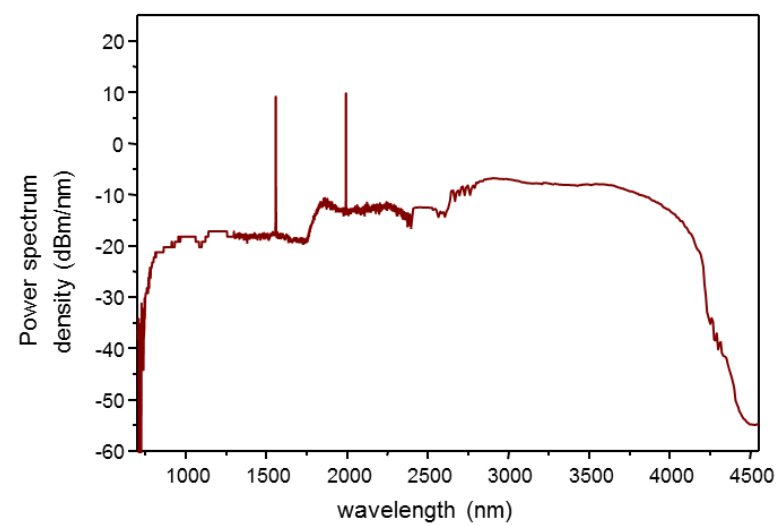

Figure 1 : Power spectral Density of the mid-IR supercontinuum laser source

\section{Spectral analyzer}

Because a supercontinuum source emits simultaneously a wide range of wavelengths, it is desirable to use a spectral analyzer benefiting of the so-called multiplex advantage, i.e either a Fourier Transform Infrared Spectrometer (FTIR) or a grating spectrograph. We have preferred the spectrograph approach, because it theoretically offers the best signal to noise ratio (for direct beam analysis at least), and it is optically simple and robust (no moving parts). 
We have used a grating spectrometer (microHR Jobin-Yvon, $140 \mathrm{~mm}$ focal length, $300 \mathrm{gr} / \mathrm{mm}, 4 \mu \mathrm{m}$ blazing angle), from which we have removed and replaced the exit slit by a linear detector array of $256 \mathrm{PbSe}$ photodiodes (pixel width $40 \mu \mathrm{m}$ and pitch $50 \mu \mathrm{m}$ ). The sensitivity of PbSe detectors extends from 1 to $5 \mu \mathrm{m}$. Linear response of the detectors has been checked and a correction curve accounting for variations of gains and efficiencies of the various pixels has been measured to flatten the array response. The array is thermoelectrically cooled to $-10^{\circ} \mathrm{C}$ into a compact packaging. The reading circuit allows digitizing and recording spectra with a line rate in the range 10-100 $\mathrm{Hz}$. The signal can also be displayed on a Labview interface in real-time, which provides a convenient mean to control and optimize SC generation and beam alignments between the ZBLAN fiber output and the detector array.

Globally, the designed spectrograph is thus able to acquire in only a few seconds typically hundreds of spectra extending on $200 \mathrm{~nm}$ with $0.8 \mathrm{~nm}$ resolution in the 3-4 $\mu \mathrm{m}$ window. In order to measure the apparatus convolution function (spectral spread function in response to a monochromatic light), we have coupled the $3.39 \mu \mathrm{m}$ emission line of a He-Ne laser into the ZBLAN fiber (instead of the $2 \mu \mathrm{m}$ pump). We have also checked that the convolution function remains unchanged across the pixel array. The optical setup and measured convolution function are shown on Figure 2.
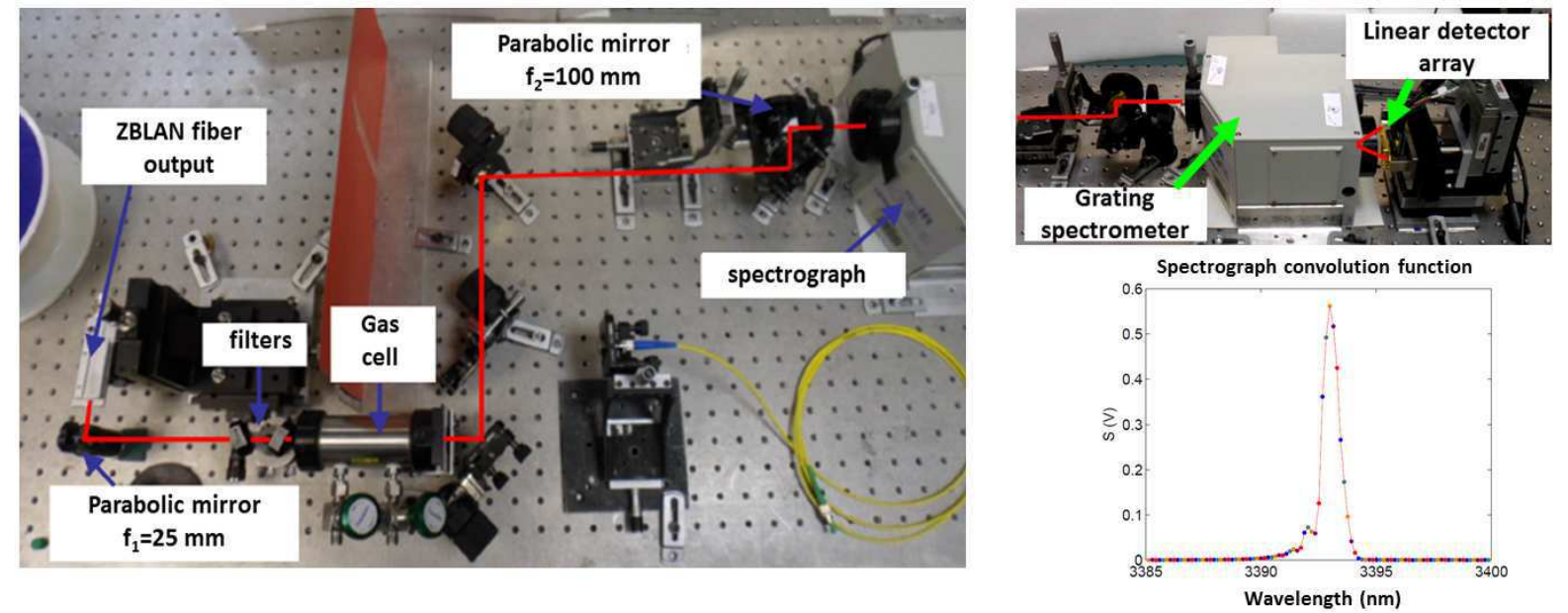

Figure 2 left : optical setup from the ZBLAN fiber output to the spectrograph entrance slit. Parabolic mirrors are used to avoid chromatic aberrations over the wide SC spectrum. Filters are used to prevent near infrared SC light from reaching the detector array by scattering or aliasing inside the spectrometer. Up-right : the spectrometer exit slit is replaced by the linear array of PbSe photodiodes. Bottom-Right : the apparatus convolution function is measured to have a $0.8 \mathrm{~nm}$ FWHM, with slight asymmetry.

\section{Processing algorithm}

We have implemented a multi-species quantification algorithm to estimate the concentrations of a gas mixture along the SC light path. It is inspired from UV DOAS literature [3], but obviously it also required some specific adaptations to process the mid-IR signals recorded with SHADOAS.

Because the SC generation process is initiated by noise fluctuations into the fluoride fiber, successive emitted spectra fluctuate randomly. Figure 3 (up-left) shows an example of 100 spectra recorded successively after absorption by a $10 \mathrm{~cm}$ gas cell filled with $\mathrm{CH}_{4}$ at 1 bar. The thickness of the displayed curve illustrates the Relative Intensity Noise (RIN) associated with SC generation. The spectral correlation degree matrix of the SC light (defined as $\rho_{i j}=\operatorname{cov}\left(S_{i}, S_{j}\right) /\left(\sigma_{i} \sigma_{j}\right)$, where $i$ and $j$ are pixel indices, and $S_{i}$ and $\sigma_{i}$ designate the signal random variable and standard deviation for pixel i) can also be directly measured. Figure 3 (up-right) shows the correlation matrix, measured from 100 spectra recorded with an empty gas cell. It shows that the mid-IR SC source has a correlation spectral distance of about $150 \mathrm{~nm}$ FWHM in the 3.3-3.5 $\mu \mathrm{m}$ window.

It appeared useful to attenuate these baseline random fluctuations (or RIN noise) by applying a Fourier highpass filter. This allows generating zero-baseline signals, easier to process. This had been discussed in a precedent LACSEA communication [4]. We have tested several algorithms for multi-species quantification from baselinefiltered signals and concluded that a Maximum-Likelihood Estimator (MLE) was both a versatile and efficient method. We have checked that statistics of baseline-filtered signals remain approximately Gaussian, such that a MLE reduces to a least-square estimator weighted by the covariance matrix. The covariance matrix of the baselinefiltered signals, contrary to non-filtered signals, is almost diagonal (see Figure 3 bottom-right). This is because the spectral correlation distance of RIN noise is large, and therefore RIN comes out as a low-frequency noise efficiently 
attenuated by the Fourier filter. Consequently, our MLE procedure empirically estimates the covariance matrix from the (hundreds of) recorded and baseline-filtered signals, and draws non diagonal elements to zero to increase numerical stability. A Levenberg-Marquardt algorithm is used to minimize the weighted least square criterion and to retrieve the gas concentration inside the gas cell. Figure 3 (bottom-left) shows an example of data fitting for a single recorded spectrum, with the gas cell filled with $\mathrm{CH}^{4}$ at 1 bar. The fit quality is good across the entire spectral window, including the saturated absorption feature at $3310-3325 \mathrm{~nm}$. By repeating the fitting procedure, an estimation histogram is built. For a 100 spectra, the pressure inside the cell is estimated to be 0.96 bar (the small $4 \%$ bias may originate from an insufficient precision during measurement of the convolution function) with a standard deviation of $1.3 \%$.
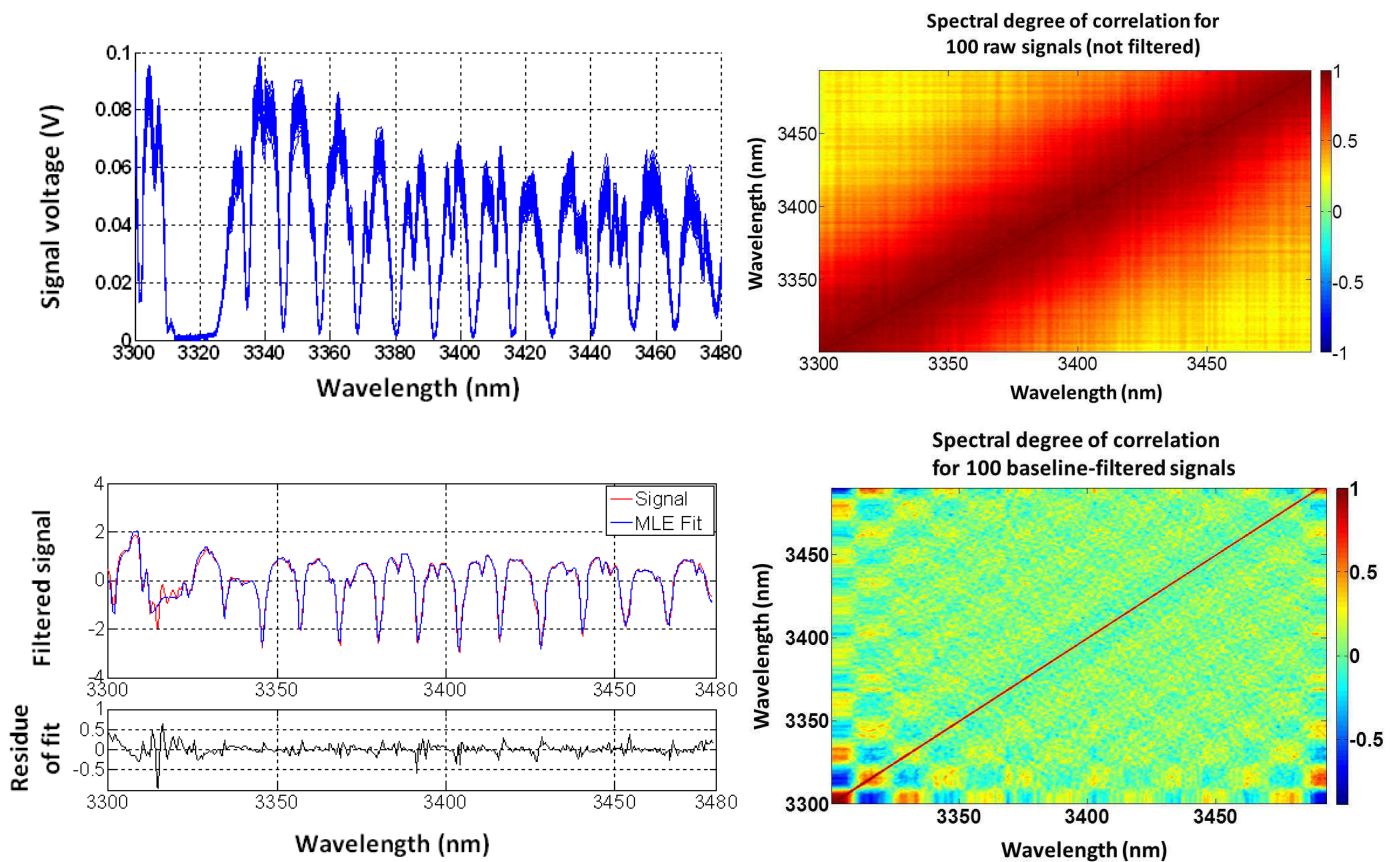

Figure 3 Up-Left: A hundred spectra recorded over the 3.3-3.5um window, after absorption by the $\mathrm{CH}_{4}$ gas cell. The RIN noise is clearly visible. Up-Right : spectral correlation degree matrix of the RIN noise (estimated from a 100 recorded spectra, with the gas cell removed for a better characterization of the input SC light alone). Bottom-left : single spectrum fitted after MLE estimation of the $\mathrm{CH}_{4}$ concentration inside the cell

The residual is small but reveals second-order persistent structures, which suggests that the fitting procedure can be improved further. Bottomright: similar to up-right but after spectral filtering (cutoff period $30 \mathrm{~nm}$ ), the matrix of spectral correlation degree is almost diagonal.

\section{Conclusion and Outlooks}

The SHADOAS test bench forms a complete and innovative platform for studying mid-IR SC signal and noise, and its applications to absorption spectroscopy with an efficient spectrographic analyzer. Future works will focus on establishing the detection limits of this technique, and will evidence experimentally a multi-species detection capability in the mid-IR. This has been already shown in near IR in ref.[4] for example.

\section{References}

[1] D.M. Brown et al., "Long-path supercontinuum absorption spectroscopy for measurements of atmospheric constituents." Opt. Express, 16, pp. 8457-5471 (2008)

[2] C.F. Kaminski, R.S. Watt, A.D, Elder, J.H. Frank, J.Hult, "Supercontinuum radiation for applications in chemical sensing and microscopy", Appl. Phys B 92, 367-378 (2008)

[3] U.Platt, "Differential Optical Absorption Spectroscopy (DOAS)”, in Air Monitoring by Spectroscopic techniques, M.Sigrist, ed. (Wiley, 1994)

[4] A. Dobroc and N. Cézard, "Signal Processing for Estimation of Gas Species using Supercontinuum Absorption Spectroscopy," in Lasers, Sources, and Related Photonic Devices, OSA Technical Digest (CD) (Optical Society of America, 2012), paper LT1B.7 